\title{
The Use of Climate Forecasts Information by Farmers in Limpopo Province, South Africa
}

\author{
Sylvester Mpandeli ${ }^{1} \&$ Phokele Maponya ${ }^{2}$ \\ ${ }^{1}$ Department of Environmental Affairs, South African Government, South Africa \\ ${ }^{2}$ Department of Environmental Science, University of South Africa, South Africa \\ Correspondence: Phokele Maponya, Department of Environmental Science, University of South Africa, South \\ Africa. E-mail: phokelemaponya@gmail.com
}

\author{
Received: September 21, 2012 Accepted: November 26, 2012 Online Published: January 15, 2013 \\ doi:10.5539/jas.v5n2p47 \\ URL: http://dx.doi.org/10.5539/jas.v5n2p47
}

\begin{abstract}
The primary aim of the paper was to examine the role of climate forecasts information as a potential tool to reduce impact of climate change in the Vhembe District in Limpopo province. A representative sample of 90 farmers participated in the study. The study involved the Vhembe District with Tshakhuma, Rabali and Tshiombo as study sites. Vhembe district is located in a semi-arid area that is frequently troubled by dry spells, often escalating into severe drought. Such situations have compelled regular assistance from the Limpopo Province in the form of drought relief. Such reactive measures are, however, costly and alternative risk-reduction measures should be sought. One alternative measure to enhance adaptive capacity and possibly improve local decision-making is seasonal climate forecasts. A tool is needed to measure how farmers have responded to past events, what techniques and methods are being used, including forecasts, and a range of other coping and adaptive mechanisms. Many recent efforts to reduce vulnerability to such events include improved adaptation and risk reduction. Farmers in the Vhembe district in Limpopo Province, South Africa (including Tshakhuma, Rabali and Tshiombo study sites) have developed their own local climate forecast strategies and adaptation practices during times of climate risks. For many years the importance of local knowledge in small-scale farmer practices was overlooked. These farmers have developed their own indicators for monitoring climate conditions such as observing the behaviour of birds, behaviour of insects and the characteristics of plants.

This paper shows how local knowledge forecasting and external knowledge forecasting can be used as a way to reduce impact of climate change. The following findings were found: (1) Local knowledge forecasting is useful to local farmers, (2) Young farmers, however, prefer to use or rely on external forecasting information, (3) Some farmers within Tshakhuma, Rabali and Tshiombo prefer to integrate both local knowledge and other types of forecasting, (4) Some farmers within the three areas use crop diversification as security measures during uncertain periods.
\end{abstract}

Keywords: climate variability, climate change, climate forecasts information, Vhembe district, Limpopo province, South Africa

\section{Introduction}

Experience across Limpopo Province shows that institutional support, climate forecast information and the role of extension officers remain areas that need serious attention. Institutional support is an important factor that needs to be structured in such a way that farmers are able to get assistance with both technical and financial information e.g. availability of inputs, technology transfer and capacity building, drought mitigation, historical rainfall distribution information and market trends. All these have an influence on the farmers' production. The majority of the resource-poor farmers depend mostly on the services of the extension officers, and this has serious consequences especially in situations where there is no institutional support. Due to the poor dissemination of information, the majority of the farmers in the study areas are using local knowledge as a way of counteracting any climate risk. Feedback from the farmers in the study shows that there are large numbers of the farmers who are ready to use external climate forecasting. As described earlier, the problem is that the way the information is disseminated creates some problems among the farming communities. External forecasting is being gradually introduced in the Vhembe district by the Agricultural Research Council, South African Weather Services and some 
academic institutions, and the majority of the farmers are beginning to change their perception about external climate information.

According to Pepin (1996), understanding the perception and categorisation of different cultures is essential to the process of meteorological information. The use of local indicators is part of the coping strategy due to the fact that external climate forecasting was inaccessible to the majority of the resource-poor farmers in the Vhembe district. Before the introduction of scientific forecasting to the Vhembe district, the majority of the farmers used local indicators as a way of predicting climate conditions. Eakin (1999), state that the use of local indicators varies from community to community and the prevalence of traditional forecasting methods reflects the demand for advance climate information to cope with climate variability in planning agricultural operations. These indicators are used as a tool to monitor climatic conditions in the areas. All the indicators are still used for probabilistic forecasts. The fact is all these indicators are based on local and cultural belief. Similar findings have been described by Luseno et al. (2000). Research conducted in Kenya indicated that some of the farmers in that country are also using local knowledge indicators in their farming activities. Farmers use indicators such as clouds, wind or lightning, that have their origins in traditional understanding of what contemporary research might recognise as atmospheric science. Others watch the behaviour of livestock, wildlife or local flora.

The objective of this paper was to examine the role of information such as climate information as a potential tool to reduce impact of climate change in the Vhembe District in Limpopo province.

\section{Materials and Methods}

This paper used both quantitative and qualitative designs as questionnaire which included matters relating to climate information forecast and farming activities was used in the interviews and Participatory Rural Appraisal (PRA) with several farmers in the area, as well as stakeholder and key informant interviews.

Three study areas were selected for this research. Tshakhuma, the first site, is an area where major horticultural crops are grown. Rabali, the second site, is a semi-arid area, farmers in this area produce different types of livestock, e.g. beef and goats. Tshiombo, the third site, farmers plant maize, groundnuts and other olericultural crops such as spinach and onion. The survey targeted ninety farmers in Vhembe District. Various phases were undertaken in the research.

\section{Phase 1}

Pre-survey visit: A pre-survey visit was arranged within the selected areas with the tribal authorities of each area. The objectives of the pre-survey visit were:

(a) To meet the tribal authorities such as headman, chief and civil organisations of the selected area;

(b) To demonstrate the objective of the survey and the content of the intended questionnaires;

(c) To introduce the survey team to the tribal authorities and to seek permission to be able to work in each of the communities;

(d) To meet agricultural officials including district officials in Limpopo Provincial Department of Agriculture and Environmental Affairs (LPDA) and officials involved in the community (e.g. extension officers).

\section{Phase 2}

Data for this study were collected over a one-year period from the communities of Tshakhuma, Rabali and Tshiombo within the Vhembe district. The data were obtained in two different but consecutive phases. Two methods were employed:

(a) Formal survey and Non-structured surveys. Farmers' surveys were conducted in three different villages in the Vhembe district (Tshakhuma, Rabali and Tshiombo). A total of 90 farmers were interviewed during the formal survey; they were chosen using random sampling techniques. Some of the questions were extracted from the survey designed by Archer (2000) during the Mangondi study in the area.

(b) The second phase of the study was a less formal and more inclusive approach using the Participatory Rural Appraisal (PRA) method. This was conducted over a period of ten days. The PRA process was made possible with the help of the Ramaano Multipurpose Training Centre (RMTC) and the Vhembe district extension officers. Unstructured questions were asked during group discussions. Respondents were not restricted to answering questions during the PRA process.

Valuable information was obtained during both the formal surveys and the PRA process, especially on aspects such as the use of local climate information, a variety of coping strategies used during drought and flood periods, the dissemination of the forecasting information previously and during the current conditions. The PRA process 
revealed distinct advantages including that the information was more reliable than when other more conventional methods were used, the information enhanced the mutual exchange of information between farmers and specialists and, finally, the information gathering became an inseparable part of the processes of planning and extension (Chambers, 1992a,b; Eakin, 1999; Vogel, 2000; Pratt, 2002; Letson et al., 2001; Phillips et al., 2001; Gadgil et al., 2002; Ziervogel et al., 2004; Ziervogel \& Downing, 2004).

During the pilot surveys there were, however, some difficulties experienced. For example, some of the farmers were not prepared to spend more than an hour being interviewed and some preferred to be interviewed in the afternoon rather in the morning scheduling of interviews thus had to be flexible. Other difficulties during the PRA process included gender divisions, a problem when trying to gain information from respondents in all three study areas. Female farmers, for example, disagreed with their male counterparts. Cultural beliefs of the people also had to be sensitively considered, e. g. pregnant women are not allowed to do field work. Some farmers suggested that in the future they would prefer to be informed about any visit three weeks in advance so that they could reshuffle their programmes. Some of the farmers, especially in the Tshiombo area, stated that they did not want to be disturbed when they were irrigating their crops due to strict water irrigation requirements from their irrigation committee. It was suggested in all the three study sites that in order to solve this difficulty in future, researchers, together with the extension officers, must inform the executive committee of the three study areas about any survey activities or research visits. Such issues are critical to remember, particularly if subsequent investigations are to be planned for this area. These suggestions from the pilot studies were included in subsequent visits and interviews.

\section{Results and Discussion}

Forecast information has been one of the major concerns of the Vhembe farming community. The majority of the farmers indicated that climate forecast information should be disseminated at least before the beginning of the season, either through the local radio stations or electronic print media. The majority of the farmers in the Vhembe district were resource-poor farmers who had no resources such as the Internet to download climate forecast information. It was suggested that local sources of information such as Phalaphala FM and Radio University Venda should be used to disseminate information but the information should not be expressed in ambiguous terms. The problem with the issue of the external climate forecast is that sometimes the information is expressed in ambiguous terms.

Some of the people who disseminate this information do not understand the interpretation and the meaning of the values of the information. The majority of the extension officers are not well-trained on climate forecast. Some of the farmers end up using local knowledge systems in order to determine the planting time, choice of cultivars and harvesting time. Farmers in many parts of the Vhembe district prefer to receive climate forecast information before the beginning of the season especially during September. This is the time when the majority of the farmers are starting to assemble seeds, fertilisers and herbicides. Farmers in the three study areas indicated that if they had external forecast information in advance, it would be easy to decide what type of seeds or crop cultivars were suitable for the coming season.

At least $80 \%$ of the respondents preferred to hear about seasonal climate outlooks during September (Figure 2). As farmers normally start to assemble inputs such as seeds and fertilisers during September and some farmers are starting to clear bushes. Agronomic crops such as maize, groundnuts and beans are also planted during this period. At least eight percent of the respondents preferred to hear about climate forecasting in August in the Tshakhuma area. Three percent of the respondents preferred to hear about climate forecasting during January, June, November and December. Farmers who preferred to hear about climate forecasting in January, June, November and December indicated that these were the months during which they tried to produce different varieties of the crops as part of their risk management strategies. These strategies assist them to generate extra source of income when the majority of the farmers are waiting to harvest their existing crops. 


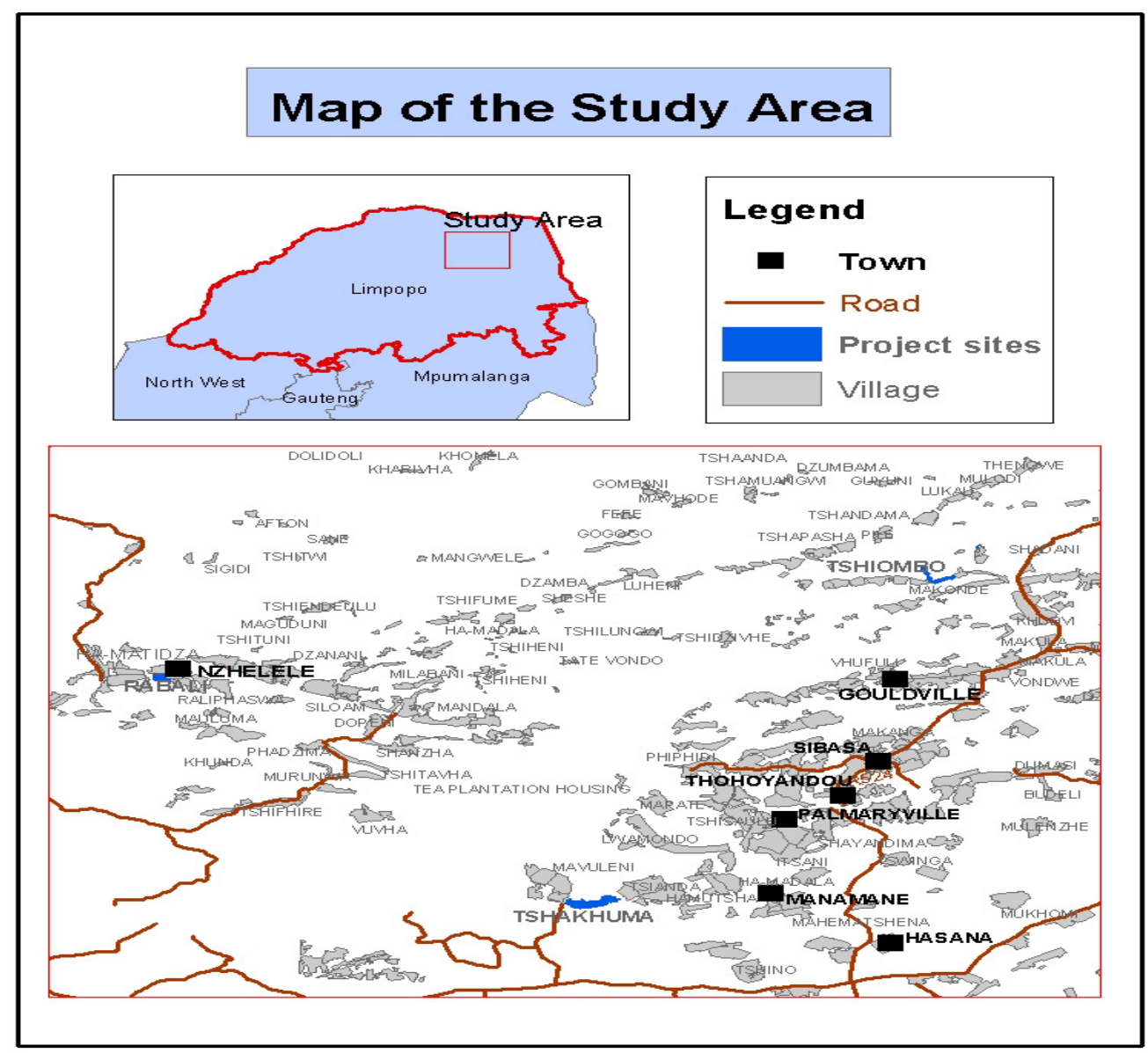

Figure 1. Map of Limpopo Province showing different villages in Vhembe district (former Venda homeland)

Source: ARC-ISCW, 2003

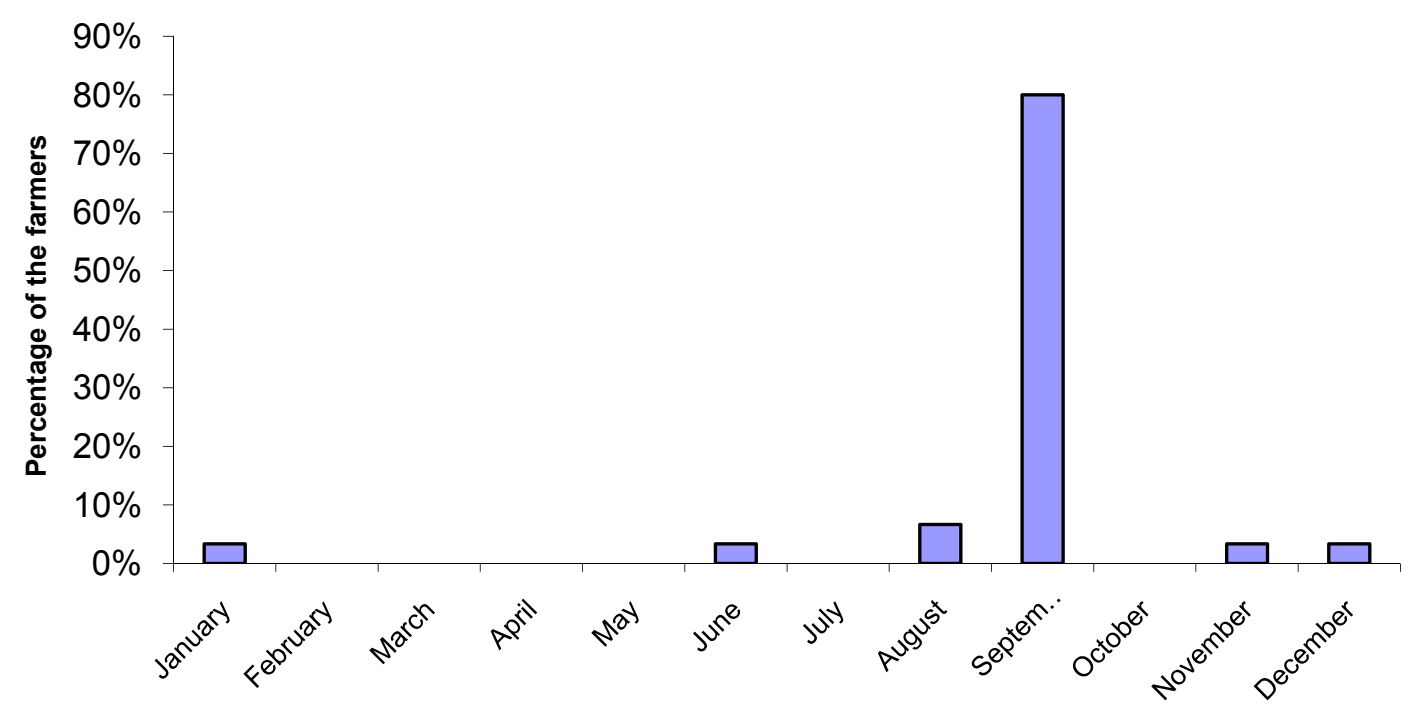

Figure 2. Different months preferred by Tshakhuma farmers to receive climate forecasting information

Another four percent of the respondents preferred to receive climate forecasts during January. These were the farmers who produced products throughout the year. Eight percent of the respondents preferred to receive forecasts in April. These farmers indicated that this was the time when they started to assemble seeds for the winter crops 
such as onions and cabbages (Figure 3). At least ten percent preferred to receive climate forecasts during June and July in order to prepare for the next season. Meanwhile, fourteen percent of the respondents would like to receive forecasts during August. Some of the farmers in the Rabali area indicated that August was important, because if they had climate forecast information in their possession they would be able to take correct decisions on whether to plant drought-tolerant crops or not. None of the respondents interviewed indicated that they would like to hear about climate forecasting during November and December (Figure 3). Some farmers stated that this was the time when the majority actually needed climate information because this could assist them to know what to expect at the end of the season in terms of yields and any natural disasters.

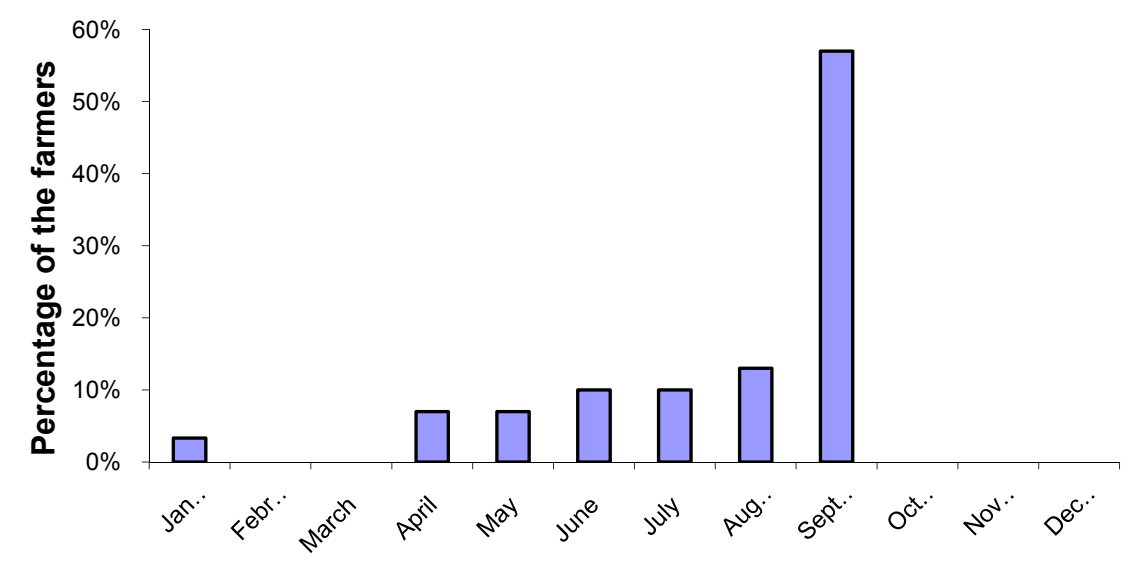

Figure 3. Different months preferred by Rabali farmers to receive climate forecasting information

At least three percent of the respondents preferred to receive external forecasting information during January. These were the farmers who would prefer to plant winter crops such as onion and cabbage. None of the respondents indicated that they would like to receive external forecasting information during February and March (Figure 4). Seven percent of the respondents stated that they would like to receive forecast information during April and May. Another thirteen percent of the respondents would like to receive the information during June. As described earlier, July to some of the farmers was the beginning of the new season, however, three percent of the respondents would like to receive external forecasting during July. At least seven percent of the respondents indicated that they would like to receive forecast information during August. The majority of the respondents (47\%) indicated that they would like to receive the external climate forecasting information in September. This was the time when the process of land preparation and seed application was done (Figure 4). The majority of farmers in the Tshiombo area normally started cleaning their land during September before the first rain comes.

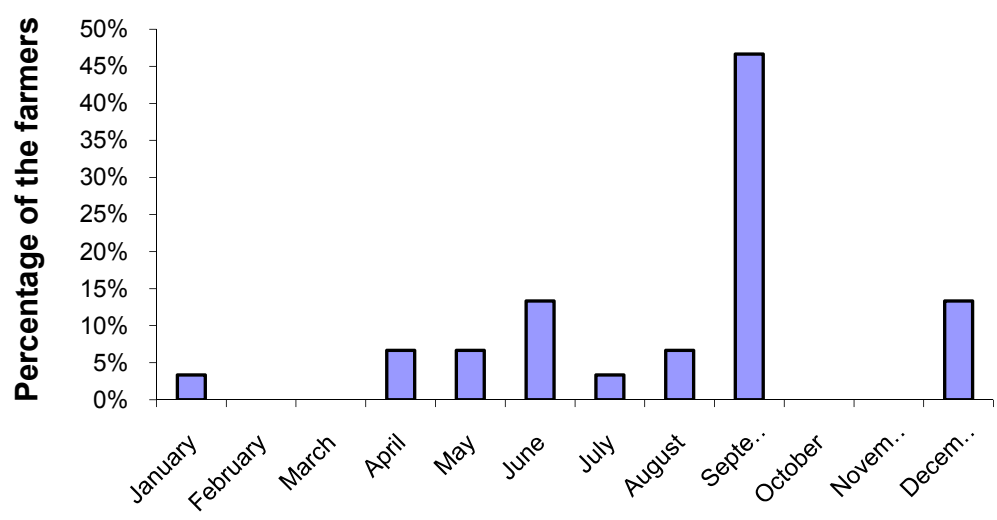

Figure 4. Different months preferred by Tshiombo farmers to receive climate forecasting information 
The first rain helps farmers to break the stalk if farmers do not practice slash and burn techniques. In the Tshiombo area, rain starts from the beginning of September until early February. Again none of the respondents indicated that they wanted to receive climate forecast during October and November, because this was viewed as late planting time, especially for maize producers. Thirteen percent of the respondents indicated that they would like to have climate information during December. December was seen as a suitable month for intercropping if the first crop was planted during September. This was done in order to avoid competition between the two crops. It was better to plant the second crop as intercropping after eight weeks as way of reducing the chance of competition. Most of the time the competition was based on the following components, sunlight, nutrient requirements, water requirements and Photosynthesis. Tshiombo farmers indicated that if there was enough irrigation water they always planted different crops throughout the year without any fear of water shortage. These farmers stated that if it rained they planted more crops, unlike farmers in the Rabali area who farmed in a dry-land area. If it did not rain there was always low production. Farmers in the Tshiombo area stated that they cleared bush or land all the time in order to reduce weeds. The use of traditional methods for climate forecasts is very popular in the Vhembe districts. Results in all the three study sites indicated that the majority of the farmers used cloud formation as one of their coping strategies. Cloud formation was perceived as the best parameter by all the farmers in all three study sites. All the farmers interviewed indicated that lack of dissemination of external forecasting in time influenced them to use traditional methods in their farming management.

Some farmers slaughter animals to read their intestines, watch the stars and moon or interpret dreams. Therefore, many of these methods were generated long ago and this led to seasonal forecasts that roughly match the time scales of external model-based forecasts (Luseno et al., 2000). Researchers such as Hatch (1983), Bharara (1994) and Osunade (1994) indicated that in order to cope with climatic variability, farmers used a series of indicators to plan production activities. Indicators such as animals, constellations, plants and abiotic factors aid farmers in planning risk management strategies. For example, Tshakhuma farmers use indicators such as cloud formation, wind behaviour, abiotic factors and other human beliefs or cultural beliefs. These indicators were developed by observations of stars and the moon, and the experiences and information passed down by previous generations constituted a local knowledge base (Hatch, 1983).

When the clouds are clustered and dark, farmers know that they will have rain within a very short period of time. Two percent of the farmers in this area indicated that if wind direction is from East to West, it means that rain is coming. At least ten percent of the respondents used different kinds of indicators in their farming activities such as animal intestines, which are clustered under "others" in Figure 5. Scientists such as Hammer et al. (2001) and Phillips et al. (2001) report other case studies in other African countries. For example, Zimbabwe farmers in 1997-1998 and again in 1998-1999 used seasonal climate forecasts elicited in advance of dry periods. This is likely to reflect the tacit scientific knowledge based on readings of clouds, wind, and flora and fauna behaviour that intersects with the explicitly scientific methods used in the climate modeling.

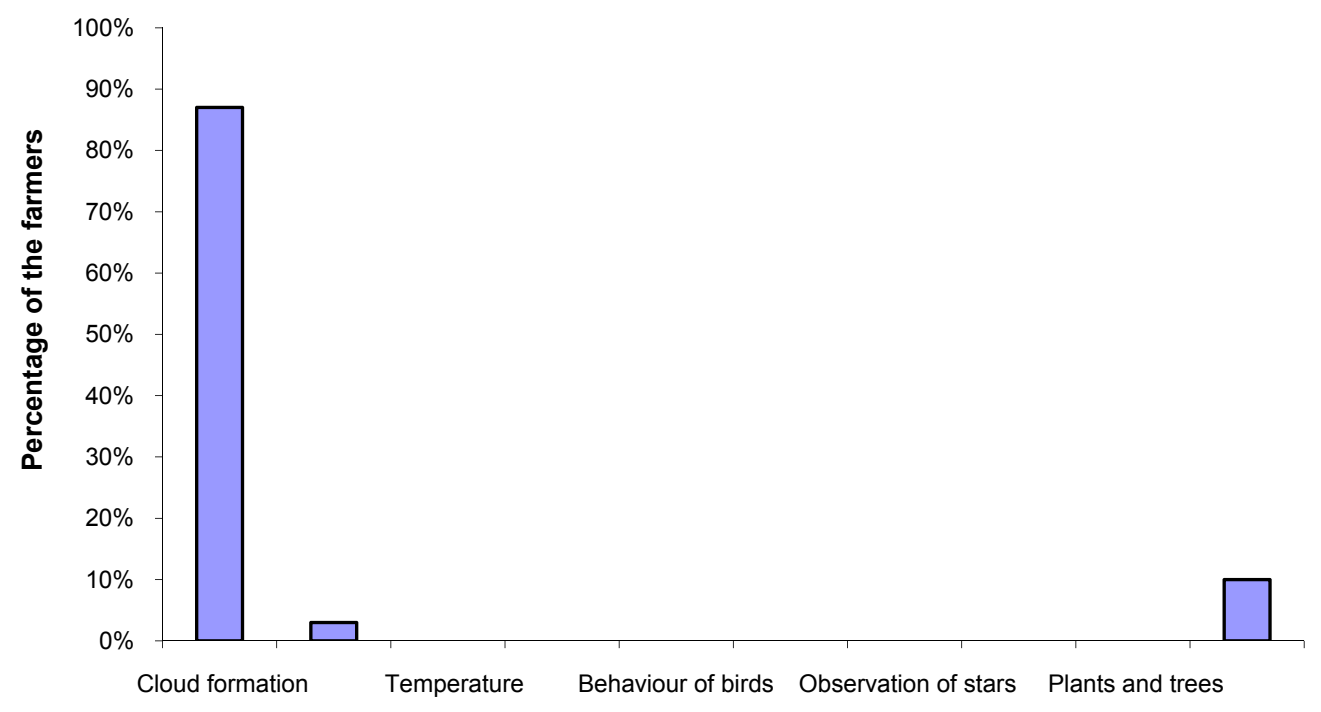

Figure 5. Traditional forecast methods use by Tshakhuma farmers 
The results indicated that $78 \%$ of the respondents in the Rabali area used cloud formation and observation as their best traditional method (Figure 6). At least six percent of the respondents indicated that wind behaviour was also used as traditional forecasting. Similar answers were given in the Tshakhuma area, if the wind direction was from East to West then old farmers knew that they would receive high rainfall. Luseno et al. (2000) in Kenya had similar findings. Another six percent of the respondents indicated that they used characteristics of plants and trees as traditional climate forecasting mechanisms. At least ten percent indicated that they used methods listed in Figure 6 as "other", such as lightening, animal intestines and fauna behaviour. These are some of the indicators mentioned by Hammer et al. (2001) and Phillips et al. (2001) in both 1997-1998 and again in 1998-1999 in Zimbabwe. Luseno et al. (2000) also mentioned lightening as one of the parameters used by Kenyan pastoralists.

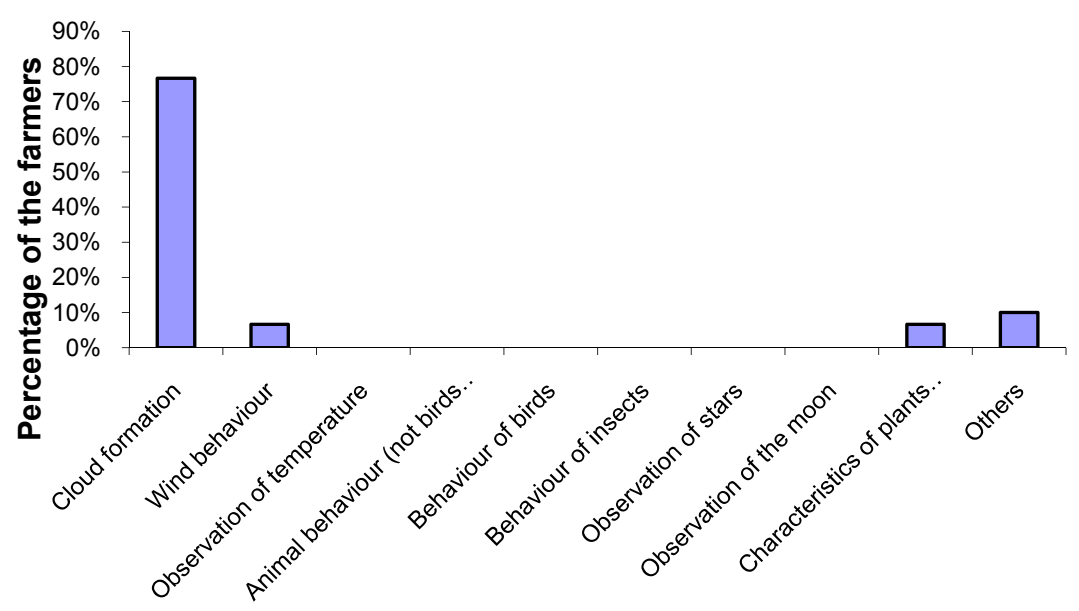

Figure 6. Traditional forecast methods use by Rabali farmers

The majority of the farmers $(68 \%)$ in the Tshiombo area used cloud formation as their indicators for climate forecasting. At least two percent used wind behaviour as local indicators (Figure 7). Another two percent of the respondents used the behaviour of insects as local indicators for climate forecasting. Old farmers in the Tshiombo area believed that if the wind comes from the western side of Tshiombo area then they would receive rain within 12 hours. These farmers also stated that the behaviour of insects such as the locust (bapu) sometimes told them that they might experience disease problems during the season (Figure 7). None of the respondents interviewed in the area mentioned animal behaviour (not birds or insects), observation of stars, observation of the moon or the characteristics of plants and trees.

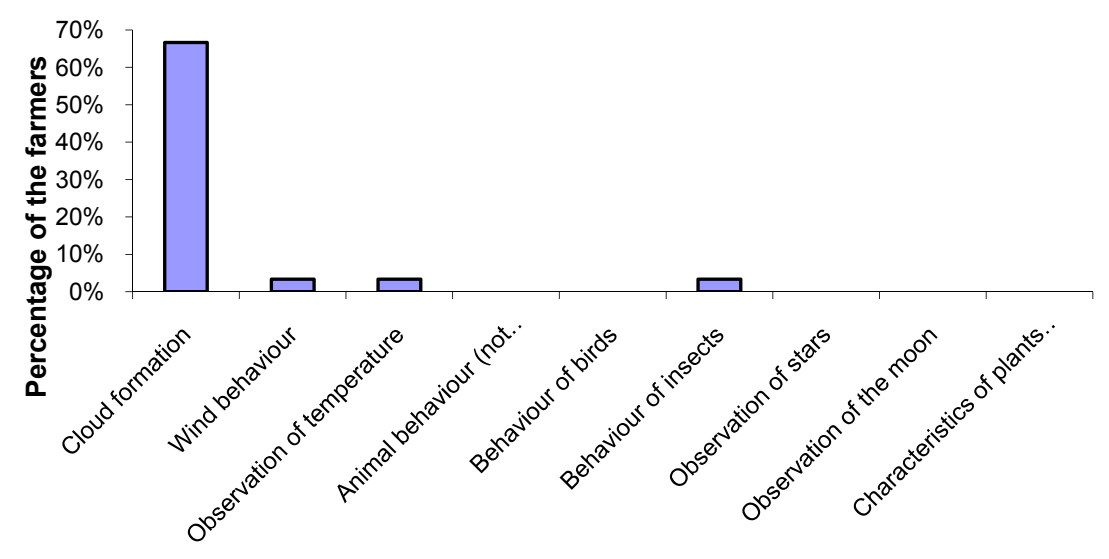

Figure 7. Traditional forecast methods use by Tshiombo farmers 


\section{Summary and Conclusion}

As stated earlier, previously the majority of the farmers in the Vhembe district used traditional knowledge forecasting in their farming business before the introduction of external forecasting. The fact that these farmers inherited their local knowledge from their grandparents influenced them to utilise local knowledge with high confidence. Since the scientific climate forecasting was introduced to these farmers, the majority of them combined local knowledge forecasting and external knowledge forecasts. The fact is, some farmers stated that it is difficult for them to abandon local knowledge and replace it with scientific knowledge completely. Some farmers perceived that local knowledge is losing value slowly and is becoming less reliable because of poor rainfall distribution and high climatic variability in the Vhembe district. Some farmers indicated that they are integrating both knowledges in order to reduce risk and increase production

Vhembe farmers have been experiencing high climatic variability several times and this influenced some of the farmers to start trying to access external climate forecast only, but some farmers use both the external climate forecast and the local knowledge climate forecast. High climatic variability in the Vhembe district affected farmers trust and confidence in using local knowledge forecast only especially on rainfall distribution. Due to poor rainfall distribution and high climatic variability, the majority of the farmers in the district are now moving away from using local knowledge forecast only. The fact that external climate forecasts can provide valuable information for crop management, planting time and the choice of cultivars influenced some to start seeking external forecast information seriously. The majority of these farmers especially young farmers are now incorporating external forecast information disseminated by the forecaster agents and the local extension officers. Some of the farmers indicated that by using external climate forecast only, this gave them high confidence even when making decisions in their farming activities. Some of the farmers in the Vhembe district.

\section{References}

Agricultural Research Council-Institute for Soil Climate Water (ARC-ISCW). (2003).

Archer, E. (2000). Again the machine has failed us: environment-development narratives and women small-scale farmers in Venda, South Africa.

Bharara, L. P. (1994). Household production strategies in a climatic variable zone.

Chambers, R. (1992a). Methods of analysis by farmers: The professional change. Institute of Development Studies. Brighton: University of Sussex,

Chambers, R. (1992b). "Relaxed and participatory rural appraisal: Notes on practical approaches and methods" in Participatory Rural Appraisal Workshop recommended reading. Pietermaritzburg: Midnat, April, 1993.

Eakin, H. (1999). Seasonal climate forecasting and the relevance of local knowledge. Physical Georgraphy, 20, 447-460.

Gadgil, S., Rao, P. R. S., \& Rao, K. N. (2002). Use of climate information for farm-level decision-making: rainfed groundnut farming in southern India. Agricultural Systems, 74, 431-457. http://dx.doi.org/10.1016/S0308-521X(02)00049-5

Hammer, G. L., Hansen, J. W., Phillips, J. G., Mjelde, J. W., Hill, H., Love, A., \& Potgieter, A. (2001). Advances in application of climate prediction in agriculture. Agricultural Systems, 70, 515-553. http://dx.doi.org/10.1016/S0308-521X(01)00058-0

Hatch, J. (1983). Our knowledge: Traditional Farming Practices in Rural Bolivia. Vol 1.

Letson, D., Llovet, I., Podestá, G. P., Royce, F., Brescia, V., Lema, D., \& Parellada, G. (2001). User perspectives of climate forecasts: crop producers in Pergamino, Argentina. Climate Research, 19, 57-67. http://dx.doi.org/10.3354/cr019057

Luseno, W. K., McPeak, J. G., Barrett, C. B., Little, P. D., \& Gebru, G. (2000). Assessing the value of climate forecast information for pastoralists: Evidence from Southern Ethiopia and Northern Kenya.

Osunade, M. A. A. (1994). Indigenous Climate Knowledge and Agricultural Practices in South-western Nigeria. Malayasian Journal of Tropical Geography, 1, 21-28.

Pepin, N. (1996). Indigenous Knowledge Concerning Weather: The example of Lesotho. Weather, 51(7), 343-348. http://dx.doi.org/10.1002/j.1477-8696.1996.tb06222.x

Phillips, J. G., Makaudze, E., \& Unganai, L. (2001). Current and potential use of climate forecasts for resource-poor farmers in Zimbabwe. In C. Rosenzweig (Ed.), Impacts of El Nino and climate variability in 
agriculture (pp. 87-100). American Society of Agronomy Special Publication no. 63, Madison, Wisconsin. http://dx.doi.org/10.1038/89416

Pratt, G. (2002). Practitioners Critical Reflections on PRA and Participation in Nepal. Institute of Development Studies: Pathways to Participation.

Vogel, C. (2000). Usable science: an assessment of long-term seasonal forecasts among farmers in rural areas of South Africa. South African Geographical Journal, $107-116$. http://dx.doi.org/10.1080/03736245.2000.9713700

Ziervogel, G., \& Downing, T. E. (2004). Stakeholder networks: improving seasonal climate forecasts. Climatic Change, 65, 73-101. http://dx.doi.org/10.1023/B:CLIM.0000037492.18679.9e

Ziervogel, G., Bithell, M., Washington, R., \& Downing, T. (2004). Agent-based social simulation: a method for assessing the impact of seasonal climate forecast application among smallholder farmers. Agricultural Systems (forthcoming). 